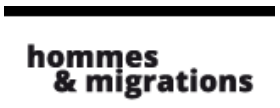

\section{Hommes \& migrations}

Revue française de référence sur les dynamiques

migratoires

$1330 \mid 2020$

1973, l'année intense

\title{
Concordance des temps
}

\section{Marie Poinsot}

\section{(2) OpenEdition \\ Journals}

\section{Édition électronique}

URL : https://journals.openedition.org/hommesmigrations/11338

DOI : 10.4000/hommesmigrations. 11338

ISSN : 2262-3353

\section{Éditeur}

Musée national de l'histoire de l'immigration

\section{Édition imprimée}

Date de publication : 17 juillet 2020

Pagination : 1

ISBN : 978-2-919040-51-3

ISSN : $1142-852 X$

\section{Référence électronique}

Marie Poinsot, "Concordance des temps », Hommes \& migrations [En ligne], 1330 | 2020, mis en ligne le 01 juillet 2020, consulté le 05 janvier 2023. URL : http://journals.openedition.org/

hommesmigrations/11338; DOI : https://doi.org/10.4000/hommesmigrations. 11338 


\section{Édito}

\section{Concordance des temps}

Marie Poinsot,

rédactrice en chef de la revue.

\section{Explorer une date de l'histoire de l'immigra-}

tion. À l'initiative de ce numéro, la revue a voulu explorer une des dates piliers proposées par le comité scientifique présidé par Patrick Boucheron pour la préfiguration de la nouvelle exposition permanente du Musée national de l'histoire de l'immigration. La revue a confié à Yvan Gastaut, fidèle compagnon sur l'histoire culturelle de l'immigration, le soin de concevoir un dossier scientifique permettant de revisiter l'année 1973, une des dates les plus significatives de l'histoire de l'immigration. La crise sanitaire mondiale est venue nous surprendre et a apporté un contexte spécifique à la parution de ce numéro que le confinement forcé pour tous les contributeurs et contributrices semble avoir mis à profit, tant les articles qui le composent sont riches et nombreux.

Le racisme comme levier. D'emblée, l'année 1973 évoque aux historiens de l'immigration le climat raciste d'une société française à peine remise des longues années de guerre d'Algérie, avec son cortège de crimes racistes, de violences policières et de montée des protestations contre l'immigration. En réaction à un contexte qui bascule dans l'adversité, les mobilisations politiques et syndicales scandent le pavé dans le sillage des années 1968 et ciblent l'immigration comme champ de luttes pour l'égalité, les droits sociaux et politiques et la dignité humaine dans une période agitée internationalement. À la densité des conflits répond une réactivité certaine des travailleurs immigrés. Ce numéro révèle d'autres images sur les immigrés assignés aux marges et au racisme. Le regard se déplace légèrement: nous ne pouvons plus les considérer uniquement sous l'angle de la résignation et du silence car cela n'est pas juste historiquement. Le domaine de la production littéraire et cinématographique offre également un miroir amplifié de la société confrontée à l'immigration. On retient habituellement de 1973 que c'est l'année qui prépare la décision de la fermeture des frontières à l'immigration de travail en 1974. Or les raisons de crise économique invoquées par l'État s'avèrent partielles, sinon partiales. Alors que la politique libérale de recrutement des travailleurs étrangers persiste après 1974 en fonction d'une l'économie française à géométrie variable, elle l'inscrit désormais dans l'irrégularité et l'absence de droits. Les véritables raisons de ce changement de cap majeur sont davantage à rechercher du côté de la peur de la contamination d'un racisme ciblant l'immigration postcoloniale et la politisation croissante des immigrés en France.

Émergences militantes. On découvre dans ce numéro que les luttes des immigrés, aux côtés des associations humanitaires, des mouvements religieux, des parties de gauche et d'extrême gauche et des syndicats, vont faire émerger un répertoire d'actions collectives prouvant sa capacité d'innovation et de métissage des registres militants. Car, en creux de ces mobilisations immigrées qui gagnent en visibilité durant cette décennie, ce sont les conditions d'une « résistance par le bas » qui s'installent dans tous les espaces de la société, dans les foyers, en usines, dans les églises et les espaces publics. Les grèves de la faim, les marches pour les droits, les festivals culturels, etc. inventent un nouveau langage d'activisme pour mobiliser au-delà des rangs habituels, plus largement dans la société, notamment auprès de la jeunesse, et acquérir les fondements d'une reconnaissance à venir. Les années 1970 constituent ainsi une séquence intense et dense d'émergences militantes qui seront transmises aux générations qui s'initient à l'arène politique dès leur plus jeune âge. Mais cette séquence sera vite oubliée des médias au profit des mémoires des marches des Beurs qui lui ont succédé.

L'immigration en temps de crise. "Concordance des temps», c'est la formule que Mustapha Harzoune reprend dans sa chronique "Kiosque», pour comparer la crise de 1973 et celle du Covid-19 que nous traversons. "Il peut être troublant de constater comment l'année 1973 et les premiers mois de 2020 peuvent entrer en résonance. Comment, selon la théorie de l'effet papillon, un battement d'aile en 1973 produira quelques effets en $2020 »$ poursuit-il. D'une crise à l'autre, ce numéro interroge les transformations des imaginaires sociaux de l'immigration. À la faveur de la crise sanitaire, tout indique qu'un certain retour du refoulé renoue avec le registre de la menace de l'ailleurs. Et la distance sociale érigée en loi sanitaire comme la répression policière contre les contrevenants à repris le lexique employé depuis plusieurs décennies pour évoquer l'immigration. Car la racine commune du mal dont il faut se protéger à tout prix et quelques soient les méthodes, c'est bien le risque de contamination venue de l'étranger. 